Pensar en Movimiento:

Revista de Ciencias del Ejercicio y la Salud EISSN 1659-4436

Vol. 14, № 2, pp. 1 - 3

Cierre al 31 de diciembre de 2016

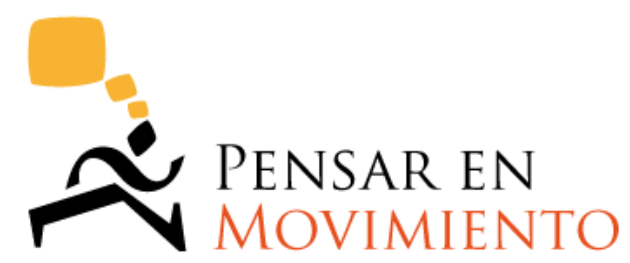

REVISTA DE CiEnCIAS DEL EJERCICIO Y LA SALUD

\title{
CIENCIA, VOLCANES, HURACANES Y PREDICCIÓN
}

En mi editorial de junio de 2014 en esta misma revista, titulado Ciencia y fútbol (Aragón-Vargas, 2014), comentaba el hecho de que los equipos de investigadores que intentaban predecir los resultados del campeonato mundial de fútbol de Brasil no lograron superar las predicciones de brujas, aficionados, ni mascotas como el pulpo Paul. En aquella ocasión reconocí que probablemente la ciencia del fútbol estaba todavía muy inmadura. Hoy quisiera profundizar un poco más en la fundamentación de la capacidad predictiva de la ciencia.

Uno de los grandes éxitos de la ciencia ha sido su poder de predicción: en las ciencias maduras, también conocidas popularmente como ciencias exactas, sabemos que, dadas ciertas condiciones, una acción determinada va a producir ciertos resultados. Eso nos ha permitido enviar hombres a la Luna (iy traerlos de regreso!), hacer trasplantes de corazón y obtener energía de los reactores nucleares. En las ciencias del movimiento humano, los científicos han logrado avances que han permitido seguir rompiendo marcas mundiales y mejorar las condiciones de vida de personas enfermas o con discapacidades físicas. Nos hemos acostumbrado tanto a la capacidad de predicción de la ciencia, que les exigimos respuestas claras a los expertos, respuestas que no siempre nos pueden dar.

Hace varios años, el volcán Turrialba despertó de su letargo y con ello despertó las inquietudes de la población: ¿qué va a pasar con este volcán en el futuro? ¿Hará una gran erupción que trastornará no solo los alrededores sino al país entero? Las respuestas de los científicos, como la que dio el Dr. Mauricio Mora, experto en geofísica y sismología volcánica en una entrevista al Semanario Universidad en octubre de este año, nos mantienen en la incertidumbre:

"No ha sido sencilla la lectura de precursores, sobre todo porque cada ciclo cambia. A nivel interno es un paso más, entonces lo que más se ha logrado ver son cambios en ciertos números de señales sísmicas pero algunas de las últimas erupciones no han tenido precursores, son bastante repentinas. Probablemente esto sea por los cambios físicos que ya ha tenido el volcán. Ha sido un proceso complejo, hubo también señales de erupción que no necesariamente terminaron en actividad." (Mora, 2016, p. 12).

También puedo citar la respuesta de la Red Sismológica Nacional:

"La Red Sismológica Nacional de Costa Rica estableció hoy dos escenarios previsibles para el futuro sobre la actividad eruptiva del volcán Turrialba, tras de casi dos meses de emanación ininterrumpida de gases y ceniza. (...) Al respecto, puntualiza que 'no es posible establecer con precisión la actividad futura del volcán. Se tienen todos los escenarios probables basados en los estudios geológicos' y con base en estadísticas mundiales. El primero de ellos apunta a un cuadro similar al de la última erupción histórica en el Siglo XIX, cuando se registró un 'índice de explosividad de grado tres' con emanaciones cuyas columnas

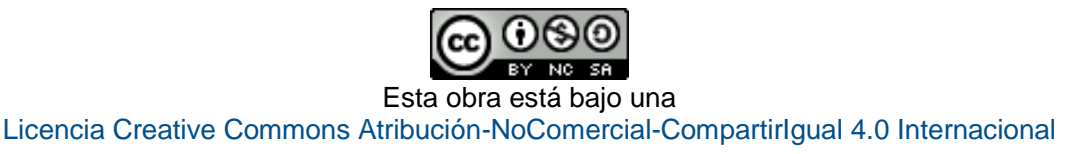


alcanzaron los cinco kilómetros de altura sobre el nivel del cráter. (...) El otro escenario contempla que el coloso continúe su actividad en ciclos eruptivos con emisiones intensas y algunos episodios explosivos alternados con fases de calma relativa como en el presente 'hasta que de nuevo entre en reposo sin que necesariamente llegue a una erupción mayor'." (Prensa Latina, San José, 4 de noviembre de 2016).

Científicos de otras latitudes, como Brad Scott de Auckland, Nueva Zelanda, han dado declaraciones similares sobre sus propios volcanes: "Puede ser que haya una erupción más pronto o más tarde, pero es casi un hecho que va a ocurrir. No se trata de si va a ocurrir, sino de cuándo (...) No hay forma de saber cuándo sucederá". Esa respuesta no se distingue mucho de la interpretación que tres meses atrás hacía un brillante colega, educador físico, sobre el mismo tema: "Estamos ante tres posibles escenarios: la actividad del Volcán Turrialba podría mantenerse, podría disminuir, o podría aumentar" (Comunicación personal).

Lejos de burlarme, lo que quiero es destacar la limitación de las predicciones en vulcanología. En el caso de los volcanes en Auckland, la predicción se complica por su magma basáltico, que pareciera subir por la corteza con mucha rapidez y por lo tanto no avisan con mucha antelación. El volcán Turrialba se ha estudiado por poco tiempo con la instrumentación actual y por lo tanto no se conoce suficientemente bien aún.

Lo mismo sucede en la Meteorología: en noviembre, todos queríamos saber cuándo y por dónde iba a llegar el huracán Otto a Costa Rica, cuál iba a ser su recorrido y cuánta fuerza iba a tener. Los expertos hicieron sus mejores predicciones aprovechando toda la información disponible, pero como pudimos constatar, la precisión dista mucho de ser perfecta. Esto se debe, en gran medida, a limitaciones propias del estado de avance de cada ciencia.

Ahora bien, la capacidad de predicción no depende solamente de la madurez de la ciencia, sino de factores ajenos a esta, independientemente de si se trata de economía, meteorología o física. Los científicos a menudo obviamos el hecho de que nuestro ejercicio de la ciencia se apoya sobre bases que no son científicas, al extremo de que se podría decir que nos apoyamos en elementos de fe: estamos convencidos de que lo que sucedió hoy volverá a suceder mañana, pero no podemos tener una prueba científica de que así será. Parafraseando a Bertrand Russell y su historia del pavo y la inducción, se podría decir que el cerdo que hemos venido cebando para la cena de Año Nuevo se equivocaría gravemente si razonara-suponiendo que puede hacerlo-que solo porque se le ha alimentado bien cada día, seguirá siendo así después de diciembre. (la idea la tomé prestada de John C. Lennox, 2009, p. 62). David Hume planteó este problema y lo llamó el problema de la inducción. Los filósofos han intentado resolver el problema de la inducción y, en general, aceptan que la única forma de justificar el pensamiento inductivo es aceptando a priori que la naturaleza es uniforme, que el mundo, como decían los griegos, es un cosmos, precisamente un todo ordenado que se comporta con regularidad. Vale la pena insistir en este punto:

"El principio de la uniformidad de la naturaleza dice que los patrones que la naturaleza exhibe en pequeña escala, los exhibirá también en gran escala. El hecho de que este trozo específico de hierro se expanda al calentarse nos dice algo no solo sobre este trozo específico, sino sobre todo el hierro. Si no presupusiéramos este principio, la ciencia se volvería imposible de inmediato. En ese caso, no tendríamos ninguna razón para pensar que la conexión causal entre hechos de tipo A y B que se realizó ayer en Ámsterdam se realizará, ceteris

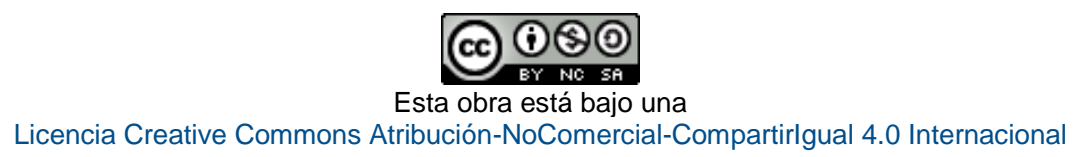


paribus, también mañana, y/o en Bruselas. Si ese principio no se presupusiera, el someter a prueba las hipótesis carecería totalmente de sentido." (Van Woudenberg, 2016, p. 11).

Sin presuponer que la uniformidad existe, es imposible hacer ciencia, pero la presuposición misma es ajena a la ciencia. En las palabras de Del Ratzsch, "la uniformidad no se puede someter a prueba, pero es esencial para el quehacer científico" (Ratzsch, 2000).

Es posible entonces ver que la ciencia misma tiene límites, que no es posible alcanzar el conocimiento exclusivamente a través del método científico. Si queremos ser intelectualmente honestos, debemos aceptar los límites de la ciencia y recurrir no solo a esta sino a la filosofía y a otras disciplinas en nuestra búsqueda de la verdad. Y por más exitosas que sean las predicciones científicas en muchos campos, debemos reconocer que también la predicción tiene sus limitaciones.

\section{Luis Fernando Aragón-Vargas, Ph.D., FACSM \\ Director, PENSAR EN MOVIMIENTO Universidad de Costa Rica}

\section{Referencias:}

Aragón-Vargas, L. F. (2014). Ciencia y Fútbol. Pensar en Movimiento: Revista de Ciencias del Ejercicio y la Salud, 12(1), 1-2. doi:http://dx.doi.org/10.15517/pensarmov.v12i1.15119

Lennox, J. C. (2009). God's Undertaker. Oxford: Lion Hudson plc.

Mora, M. (2016). Entrevista. Semanario Universidad, 5 de octubre de 2016. Recuperado de http://semanariouniversidad.ucr.cr/universitarias/red-sismologica-pide-calma-ante-mensajesalarmistas/

Prensa Latina (2016). Autoridades ticas en permanente vigilancia sobre volcán Turrialba. Recuperado de http://prensa-latina.cu/index.php?o=rn\&id=39328\&SEO=autoridades-ticas-enpermanente-vigilancia-sobre-volcan-turrialba

Ratzsch, D. (2000). Science \& its Limits: The Natural Sciences in Christian Perspective (Segunda Edición). Downers Grove, IL: InterVarsity Press. [Versión Kindle para PC]. Recuperado de www.amazon.com

Scott, B. (2016). Not If, but When. Recuperado de http://www.aucklandmuseum.com/whatson/exhibitions/volcanoes/city-of-volcanoes/not-if,-but-when

Van Woudenberg, R. (2016). Los límites de la ciencia y su relación con la fe cristiana. Repositorio institucional Kérwá, Universidad de Costa Rica. Recuperado de http://kerwa.ucr.ac.cr/handle/10669/29393 